\title{
| A educação permanente no servị̧o de enfermagem em emergência
}

\author{
|Permanent education in the service of emergeney nursing
}

\section{Simony Fabiola Lopes Nunes}

\section{Resumo}

A educação permanente em saúde tem por base a atuação e a reflexão da realidade vivenciada no cotidiano da assistência dos profissionais da saúde de modo a transformar a realidade por meio da problematização. A presente investigação é uma revisão integrativa que objetivou analisar as publicações científicas acerca da educação permanente para os trabalhadores de enfermagem no serviço de emergência, indexados em bancos de dados no período de 2005 a 2010. Foram pesquisadas as bibliotecas virtuais MEDLINE, LILACS e SCIELO. Após análise dos artigos incluídos na revisão os resultados dos estudos apontaram que a Educação Permanente cria espaços de reflexão para que os profissionais procurem novas estratégias de intervenção e caminhos para a superação de dificuldades individuais e coletivas no serviço.

\section{Abstract}

Permanent education in heal this based on the performance and reflection of the reality experienced in the daily care of health professionals in order to transform reality through the questioning. The present investigation is a literature review aimed to analyze the scientific literature on continuing education for nursing staff in the emergency department, indexed in data bases in the period 2005 to 2010.Virtual libraries were searched MEDLINE, LILACS and SciELO. After analyzing the article is included in the review the results of studies indicated that the Continuing Education creates opportunities for reflection for professionals to seek new intervention strategies and ways to over come difficulties in individual and collective service.

Deseritores: Enfermagem em Emergêneia, Servị̧os Médieos de Emergêneia, Serviço Hospitalar de Educação, Euducação em Enfermagem.

Keywords: Emergeney Nursing; Emergeney Medieal Serviees; Education Service Hospital; Nursing Education

Enfermeira especialista na modalidade Residêneia em Serviẹos de Saúde. Professora auxiliar departamento de enfermagem CCSST/UFMA.

Para correspondência:

Simony Fabiola Lopes Nunes

E-mail: sifabiolanunes@yahoo.com.br 
Introduẹão

Observamos que no processo dos serviços de educação hospitalar, termos como treinamento em serviço, educação no trabalho, educação em serviço, educação continuada e educação permanente apresentam - se com significados semelhantes, sendo utilizados quer para os programas de capacitação inicial para o trabalho ou como de atualização continuada, bem como aparecendo nos organogramas efetivos das instituições hospitalares.

$\mathrm{O}$ aprender e o ensinar se incorporam ao cotidiano das organizações e ao trabalho quando se fala em Educação Permanente (EP). Sendo esta fundamentada em diferentes vertentes teóricas, onde se destaca as grandes contribuições de Paulo Freire, especialmente nos conceitos de ensino problematizador e de aprendizagem significativa, na qual se levam em consideração os conhecimentos e as experiências que as pessoas já possuem ${ }^{1}$. A EP gera a reflexão, o profissional pode repensar sua prática, entender os processos de trabalho no qual estão inseridos, assim, tendo a possibilidade de repensar condutas, de buscar novas estratégias de intervenção e perseguir a superação de dificuldades individuais e coletivas.

Pode-se entender por educação permanente toda e qualquer atividade que tem por objetivo provocar uma mudança de atitudes e/ou comportamento a partir da aquisição de novos conhecimentos, conceitos e atitudes². É uma das estratégias que promove um espaço reflexivo critico, ao partir da problematização para favorecer a continuidade transformadora da realidade $^{2-3}$. Desta forma, a educação permanente pode ser definida como um continuo aprendizado em serviço, que proporciona alteração de comportamento a partir da aquisição de novos conhecimentos, que na Reforma Sanitária Brasileira, ganhou um conceito pedagógico ampliado para executar a integração entre ensino e as ações e serviços, bem como entre docência e atenção à saúde, sendo útil para a formação e gestão setorial, desenvolvimento institucional e controle social em saúde ${ }^{4}$.

No âmbito da saúde e enfermagem, as atividades educativas são abordadas com base na concepção da educação permanente (EP) aderidas como política pública de formação e desenvolvimento de trabalhadores para o SUS, de acordo com a Portaria GM/MS no. 1.996 de 20 de agosto de 2007. Com ela uma visão pedagógica deste processo educativo nos permite analisar o cotidiano de trabalho e da formação em saúde considerando as relações concretas que operam a realidade e a construção de espaços coletivos no interior das equipes para reflexão e avaliação do sentido das práticas no cotidiano de trabalho. Pois o trabalho é o elo que une e articula o conhecimento, o desempenho do trabalhador, desenvolvendo-lhe um novo saber, assim a aprendizagem é uma dinâmica contínua ${ }^{5}$.

Nesse contexto as políticas públicas são ferramentas utilizadas como estratégia para potencializar a disseminação global do conhecimento, provocando o intercâmbio com o resto do mundo, conduzindo a individualização de seu acesso e aprendizado e promovendo a atualização profissional são as tecnologias da informação. Desta forma, o serviço de urgência e emergência pode utilizar deste instrumento, por requerer desenvolvimento da capacidade de flexibilidade e adaptabilidade das transformações 4 .

Sabemos que a formação e a qualificação dos profissionais que atuam nos serviços de urgência e emergência são preocupações dos gestores, visto que as opções existentes no âmbito da preparação para formadores nesse serviço são insuficientes. Por essa razão, é comum que profissionais da saúde, ao se encontrarem em uma situação de urgência de maior gravidade, tenham o impulso de encaminhá-la rapidamente, em muitos casos, para uma unidade de maior complexidade, antes de realizar uma avaliação prévia e da estabilização do quadro ${ }^{6}$.

A literatura afirma que a equipe de enfermagem do serviço de urgência e emergência deve ser caracterizada pelo conhecimento e experiência em clínica médica e clínica cirúrgica; capacidade de trabalhar em equipe; destreza, rapidez e agilidade; para avaliar e priorizar o atendimento; deve ser segura e centrada, além de possuir autoconfiança e capacitação profissional ${ }^{7}$.

Dentro da Política Nacional de Atenção às Urgências, os Núcleos de Educação em Urgências (NEU) devem se organizar como espaços de saber interinstitucional na formação e capacitação, habilitação e educação continuada de recursos humanos para as urgências e emergências. Sobre 
alguns dos objetivos principais dos Núcleos de Educação em Emergência para o aprimoramento e desenvolvimento do profissional de saúde podemos destacar a promoção de programas de formação e educação continuada na forma de treinamento em serviço; criação de equipes multiplicadoras e o desenvolvimento e aprimoramento de forma participativa e sustentadas as políticas públicas voltadas para o setor emergencial ${ }^{5}$.

Com o surgimento de novos modelos de gestão, consequentemente, novas abordagens gerenciais também aparecem, como a gestão participativa, os programas de qualidade e a descentralização das decisões e aproximação de todos os integrantes da equipe de trabalho. A EP norteia a oportunidade de participação do trabalhador na discussão, na tomada de decisões e no aperfeiçoamento constante do processo de trabalho. É necessário que haja o investimento nos trabalhadores, oportunizando uma aprendizagem contínua, para satisfazerem suas necessidades pessoais e profissionais, traçando as melhores estratégias no coletivo para intervirem de forma a solucionar as necessidades dos usuários ${ }^{8}$.

Analisando esta realidade, estudos ${ }^{9-10}$ mencionam que os profissionais que trabalham em serviços de saúde precisam estar preparados tecnicamente e eticamente para prestar um atendimento adequado, respeitando os direitos do paciente. No setor de urgência e emergência os profissionais devem estar capacitados, pois o cliente corre mais facilmente o risco dos seus direitos serem ameaçados em razão da complexidade desse setor ${ }^{10}$.

Considerando a prática assistencial na emergência, podemosdestacar que, para os profissionais, a emergência compreende um local que possibilita capacitação e troca de experiência, com companheiros mais capacitados ou mesmo com outros membros da equipe ${ }^{11}$. Por outro lado, estudos ${ }^{12}$ constatam a necessidade de treinamento técnico-cientifico especifico aos profissionais que atuam nas Unidades de Emergência, objetivando o autoconhecimento, visto que são profissionais que se encontram em constante situações em que são necessárias controle de emoções, bem como reconhecimento dos seus limites.

Este trabalho nasceu do interesse em aprofundar os conhecimentos a respeito da educação permanente dos enfermeiros nos serviços de emergência destinada ao atendimento de adultos, considerando que os emergencistas, em especial a equipe de enfermagem, têm maior tendência a priorizar os aspectos imediatos e técnicos, despreocupando-se, em algumas situações, com questões cientificas e éticas. Quanto à relevância do estudo, decorre esta do fato de a assistência emergencial ser uma modalidade que consiste na observação estrita e contínua de pessoas criticamente enfermas, levando ao profissional que ali trabalha.

Desta forma, o presente estudo teve por objetivo analisar a educação permanente nos serviços de enfermagem na emergência retratados nesses estudos objetivos.

\section{Metodologia}

Este estudo consiste em uma revisão integrativa da literatura. Esse tipo de revisão permite compendiar o conhecimento estabelecido acerca de determinados assuntos.

O levantamento do estudo ocorreu no período de março a maio de 2011. Sendo utilizadas 06 (seis) etapas na elaboração desta revisão integrativa: formulação da questão norteadora da pesquisa, a revisão nas bases de dados, identificação dos estudos a serem incluídos na revisão, por seguinte a seleção e avaliação dos estudos encontrados, a coleta dos dados e análise e síntese dos dados, conforme fluxograma abaixo.

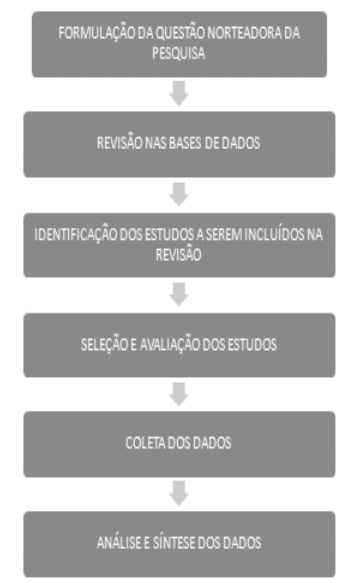

Figura 1. Fluxograma de elaboração para revisão integrativa. 
A partir da questão hipotética ("qual o conhecimento produzido e publicado na literatura nacional sobre a educação permanente em saúde nos serviços de urgência e emergência?"), iniciamos a busca por literatura que pudesse contribuir para elucidar o questionamento. Para isso foram consultados periódicos nacionais, que analisassem e discutissem a educação permanente nos serviços de enfermagem, destacando como a equipe de enfermagem relaciona-se com essa modalidade de educação na emergência. As bases de dados consultadas foram: BDENF (Base de Dados Bibliográficos Especializada na Área de Enfermagem do Brasil), LILACS (Literatura Latino-Americana e do Caribe em Ciências da Saúde), MEDLINE (Medical Literature Analysis and Retrieval Sistem on-line), SCIELO (Scientific Eletronic Library Online) e BVS (Biblioteca Virtual de Saúde). Integralidade a partir dos seguintes descritores: Enfermagem em Emergência; Serviços Médicos de Emergência, Serviço Hospitalar de Educação, Educação em Enfermagem.

\begin{tabular}{|c|c|}
\hline Base de Dados & Descritor \\
\hline \multirow{10}{*}{$\begin{array}{l}\text { BDENF, } \\
\text { MEDLINE, } \\
\text { LILACS, SCIELO }\end{array}$} & $\begin{array}{l}\text { Enfermagem em Emergência e Serviços } \\
\text { Médicos de Emergência }\end{array}$ \\
\hline & $\begin{array}{c}\text { Enfermagem em Emergência e Serviço } \\
\text { Hospitalar de Educação }\end{array}$ \\
\hline & $\begin{array}{l}\text { Enfermagem em Emergência e } \\
\text { Educação em Enfermagem }\end{array}$ \\
\hline & $\begin{array}{l}\text { Serviços Médicos de Emergência e } \\
\text { Serviço Hospitalar de Educação }\end{array}$ \\
\hline & $\begin{array}{l}\text { Serviços Médicos de Emergência e } \\
\text { Educação em Enfermagem }\end{array}$ \\
\hline & $\begin{array}{l}\text { Serviço Hospitalar de Educação e } \\
\text { Educação em Enfermagem }\end{array}$ \\
\hline & Enfermagem em Emergência \\
\hline & Serviços Médicos de Emergência \\
\hline & Serviço Hospitalar de Educação \\
\hline & Educação em Enfermagem \\
\hline \multirow{4}{*}{$\begin{array}{l}\text { BVS } \\
\text { INTEGRALIDADE }\end{array}$} & Enfermagem em Emergência \\
\hline & Serviços Médicos de Emergência \\
\hline & Serviço Hospitalar de Educação \\
\hline & Educação em Enfermagem \\
\hline
\end{tabular}

Quadro 1. Descritores utilizados nas bases de dados.

Imperatriz, MA, 2005 - 2010.

No Quadro 1 encontra-se a combinação de indexadores utilizada na pesquisa, avaliando que a BVS integralidade tem como finalidade divulgar documentos de importância para a construção da integralidade da educação permanente em saúde, nessa base de dados a busca foi realizada com os descritores Enfermagem em Emergência, Serviços Médicos de Emergência, Serviço Hospitalar de Educação e Educação em Enfermagem isoladamente.

Na primeira etapa da busca foram capturados 96 artigos nas bases de dados, os quais foram lidos na íntegra, conferindo com o objetivo principal do estudo. Após, ocorreu o aprimoramento, excluindo-se os artigos que não atenderam aos critérios, restando 09 estudos que atenderam ao escopo da revisão.

Estabelece-se como critérios de inclusão para seleção dos estudos: relacionarem-se a educação permanente no contexto hospitalar, envolvendo a equipe de enfermagem; pesquisas realizadas por enfermeiros; estudos teóricos em humanos adultos acima de 19 anos; terem sido publicadas nos últimos cinco anos; entre os anos de 2005 e 2010; acesso livre ao artigo e serem publicadas em português.

Para análise utilizou-se a análise temática dos dados com leitura prévia do resumo seguida da leitura detalhada dos artigos, que consentiu a identificação de afinidades que compuseram as seguintes temáticas de análise: a Educação Permanente na Emergência e a Importância da Educação Permanente para a Equipe que atua nos Serviços de Emergência. Para melhor visualização foi elaborado um banco de dados, construindo-se um arquivo eletrônico dos estudos encontrados, permitindo-se a tabulação conforme os critérios de interesse, como: título, autor, o período de publicação, periódico em que foram publicados, sujeitos da pesquisa, região, metodologia.

A apresentação dos resultados e discussão dos dados obtidos foi feita de forma descritiva, possibilitando a avaliação da aplicabilidade da revisão integrativa elaborada, de forma a atingir o objetivo desse método.

\section{Resultados e Diseussão}

Seguindo a estratégia definida, o objetivo do estudo e critérios de inclusão, a busca integrativa resultou em 09 (nove) estudos identificados na referência desse trabalho.

Em relação ao delineamento da pesquisa, constatamos 01 relato de experiência, 01 estudo de revisão, 01 estudo baseado em opinião de 
especialista, 06 estudos de abordagem qualitativa. No quadro 2 apresenta-se a síntese dos artigos indexados incluída na presente revisão integrativa, com os respectivos autores $\mathrm{e}$ delineamentos. Todos os artigos foram lidos na íntegra e selecionados somente aqueles que incluíam os aspectos relacionados à educação permanente na emergência.
Dentre os artigos incluídos nesta revisão integrativa, 08 (oito) artigos são de autoria de enfermeiros e 01 não foi possível identificar a categoria profissional. Quanto ao tipo de periódico, 08 (oito) artigos foram publicados em periódicos de enfermagem e 01 foi publicado em periódico de saúde coletiva.

Como já mencionado, as categorias construídas a partir do agrupamento das ideias

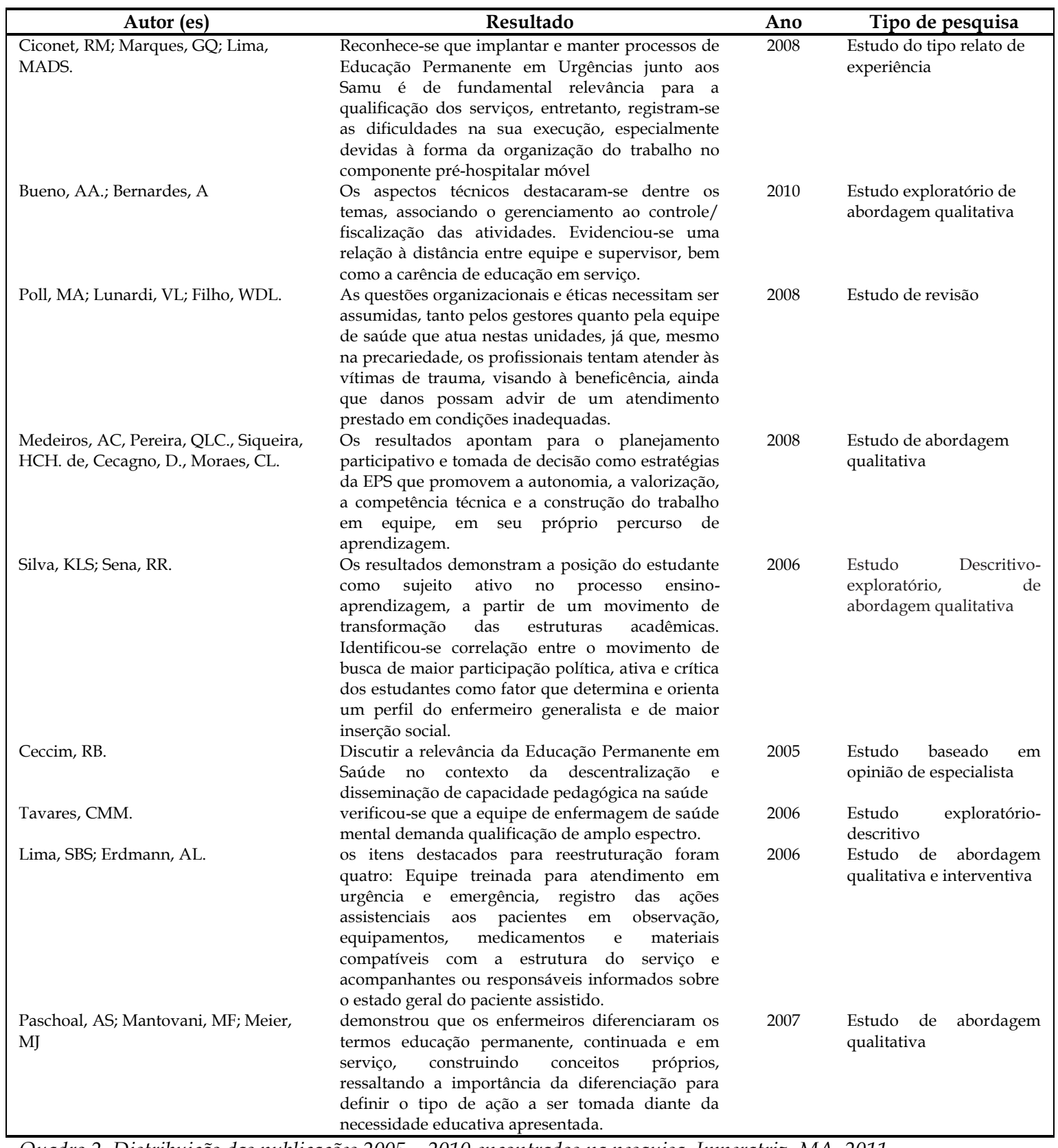

Quadro 2. Distribuição das publicações 2005 - 2010 encontrados na pesquisa. Imperatriz, MA, 2011.

Fonte: pesquisa direta 


\begin{tabular}{|c|c|c|}
\hline Autor (es) & Objetivo & Principais resultados \\
\hline $\begin{array}{l}\text { Medeiros, AC, Pereira, QLC, } \\
\text { Siqueira, HCH, Cecagno, D, } \\
\text { Moraes, CL }\end{array}$ & $\begin{array}{l}\text { Conhecer as estratégias de gestão, com base na } \\
\text { Educação Permanente em Saúde. }\end{array}$ & $\begin{array}{l}\text { O planejamento participativo e tomada } \\
\text { de decisão são vistos como estratégias } \\
\text { da EPS. }\end{array}$ \\
\hline Lima, SBS; Erdmann, AL & $\begin{array}{l}\text { Construir ações de enfermagem para reestruturar } \\
\text { o Pronto Socorro de um hospital universitário de } \\
\text { acordo com os padrões da Acreditação Hospitalar } \\
\text { em urgência e emergência segundo o Ministério } \\
\text { da Saúde. }\end{array}$ & $\begin{array}{l}\text { Para reestruturar o setor,deve-se } \\
\text { apresentar: Equipe treinada para } \\
\text { atendimento em urgência e emergência, } \\
\text { registro das ações assistenciais aos } \\
\text { pacientes em observação, } \\
\text { equipamentos, medicamentos e } \\
\text { materiais compatíveis com a estrutura } \\
\text { do serviço e acompanhantes ou } \\
\text { responsáveis informados sobre o estado } \\
\text { geral do paciente assistido. }\end{array}$ \\
\hline Silva, KLS; Sena, RR & $\begin{array}{l}\text { Retratar mudanças que são percebidas nos } \\
\text { estudantes durante a formação e que contribuem } \\
\text { para a definição de um perfil profissional. }\end{array}$ & $\begin{array}{l}\text { A posição do estudante como sujeito } \\
\text { ativo no processo ensino-aprendizagem. } \\
\text { Identificou-se correlação entre o } \\
\text { movimento de busca de maior } \\
\text { participação política, ativa e crítica dos } \\
\text { estudantes como fator que determina e } \\
\text { orienta um perfil do enfermeiro } \\
\text { generalista e de maior inserção social. }\end{array}$ \\
\hline Tavares, CMM & $\begin{array}{l}\text { Analisar a necessidade de educação permanente } \\
\text { da equipe de enfermagem para o cuidar nos } \\
\text { serviços de saúde mental. }\end{array}$ & $\begin{array}{l}\text { A equipe de enfermagem de saúde } \\
\text { mental demanda qualificação de amplo } \\
\text { espectro, e que, educação permanente } \\
\text { da equipe de enfermagem de saúde } \\
\text { mental exige além de programas } \\
\text { educacionais baseados em definição de } \\
\text { competências específicas. }\end{array}$ \\
\hline
\end{tabular}

Quadro 3. Distribuição das publicações 2005 - 2010 associadas a educação permanente em saúde, segundo autoria, objetivos e principais resultados. Imperatriz, MA, 2011.

Fonte: Pesquisa direta

centrais encontradas nos estudos foram: a Educação Permanente na Emergência e a Importância da Educação Permanente para a Equipe que atua nos Serviços de Emergência.

\section{A educação permanente na emergêneia}

$\mathrm{Na}$ categoria Educação Permanente na Emergência foram incluídos os trabalhos que abordavam a estratégia desse tipo de educação no serviço de urgência e emergência. No quadro 3 apresenta-se as publicações associadas a educação permanente em saúde, segundo autoria, objetivos e principais resultados da categoria Educação Permanente na Emergência.

O crescente número de acidentes e violência tem gerado forte impacto no SUS e na sociedade. No que diz respeito a este impacto, ele pode ser observado e mensurado pelo aumento dos gastos com internação hospitalar, assistência em Unidade de Terapia Intensiva e pela longa permanência hospitalar deste perfil de paciente. No âmbito social pode ser percebido pelos elevados índices de mortalidade por acidentes e violências nos últimos anos. Ocorrendo assim, uma sobrecarga na área de atendimento emergencial, por isso, a importância da capacitação do profissional desta área ${ }^{5}$.

Com o surgimento de novos modelos de gestão, consequentemente, novas abordagens gerenciais também aparecem, como a gestão participativa, os programas de qualidade e a descentralização das decisões e aproximação de todos os integrantes da equipe de trabalho. E nesse contexto, a Educação Permanente norteia a oportunidade de participação do trabalhador na discussão, na tomada de decisões e no aperfeiçoamento constante do processo de trabalho. É necessário que haja o investimento nos trabalhadores oportunizando uma aprendizagem contínua para satisfazerem suas necessidades pessoais e profissionais, traçando as melhores estratégias no coletivo para intervirem de forma a solucionar as necessidades dos usuários ${ }^{8}$.

Autores de um estudo ${ }^{12}$ que analisava as estratégias de enfermagem na busca da 


\begin{tabular}{|c|c|c|}
\hline Autor (es) & Objetivo & Principais resultados \\
\hline $\begin{array}{l}\text { Paschoal, AS.; Mantovani, M; } \\
\text { Meier, MJ. }\end{array}$ & $\begin{array}{l}\text { Discutir a concepção de educação permanente, } \\
\text { continuada e em serviço junto a enfermeiros de } \\
\text { um hospital de ensino. }\end{array}$ & $\begin{array}{l}\text { Os enfermeiros conseguiram diferenciar os } \\
\text { termos educação permanente, continuada e em } \\
\text { serviço, formando conceitos próprios, } \\
\text { observando a importância da diferenciação } \\
\text { para determinar o tipo de ação a ser tomada } \\
\text { diante da necessidade educativa apresentada }\end{array}$ \\
\hline $\begin{array}{l}\text { Ciconet, RM; Marques, GQ; } \\
\text { Lima, MADS. }\end{array}$ & $\begin{array}{l}\text { Relatar a experiência da Educação Permanente } \\
\text { com trabalhadores de um serviço de atendimento } \\
\text { pré-hospitalar móvel de urgência de Porto } \\
\text { Alegre. }\end{array}$ & $\begin{array}{l}\text { Reconhece que implantar e manter processos } \\
\text { de Educação Permanente em Urgências junto } \\
\text { aos SAMU é de fundamental relevância para a } \\
\text { qualificação dos serviços, entretanto, registra as } \\
\text { dificuldades na sua execução. }\end{array}$ \\
\hline Bueno, AA.; Bernardes, A & $\begin{array}{l}\text { Caracterizar o gerenciamento do enfermeiro neste } \\
\text { serviço de acordo com a visão dos profissionais } \\
\text { da equipe enfermagem. }\end{array}$ & $\begin{array}{l}\text { A carência de educação em serviço e a distância } \\
\text { entre equipe e superviso. }\end{array}$ \\
\hline $\begin{array}{l}\text { Poll, MA; Lunardi, VL; Filho, } \\
\text { WDL. }\end{array}$ & $\begin{array}{l}\text { Apresentar uma reflexão sobre questões } \\
\text { organizacionais, e, possíveis implicações éticas, } \\
\text { que permeiam a prática da equipe de saúde, em } \\
\text { uma unidade de urgência/emergência, no } \\
\text { atendimento a vítimas de trauma decorrente de } \\
\text { acidente e/ou violência. }\end{array}$ & $\begin{array}{l}\text { Constatou-se que as questões organizacionais e } \\
\text { éticas necessitam ser assumidas, pelos gestores } \\
\text { e pela equipe de saúde que atua nestas } \\
\text { unidades. }\end{array}$ \\
\hline Ceccim, RB & $\begin{array}{l}\text { Apresentar o modo como foi produzida uma } \\
\text { política pública nacional de Descentralização e } \\
\text { disseminação de capacidade pedagógica no si s } \\
\text { tema único de saúde. }\end{array}$ & \\
\hline
\end{tabular}

Quadro 4. Distribuição das publicações 2005 - 2010 associadas a educação permanente em saúde, segundo autoria, objetivos e principais resultados. Imperatriz, MA. 2011.

Fonte: pesquisa direta

acreditação hospitalar no serviço de urgência e emergência constataram que pela educação no local de serviço ser a principal estratégia para facilitar a atualização dos conhecimentos por a apreensão e a interpretação da realidade que o cerca, é importante que a equipe de saúde participe da capacitação como pré-requisito de permanência no serviço, por meio de serviços de educação continuada nos hospitais.

As diretrizes gerais que norteiam a educação dos profissionais de saúde do século XXI descrevem que o desenvolvimento de competências deve estar dirigido à busca da integralidade da atenção à saúde, contribuindo para a formação de um profissional que agregue aptidões para tomada de decisão, comunicação, liderança, gerenciamento e educação permanente. Nesse sentido, o processo de trabalho em saúde tem como característica a contemporaneidade, a complexidade e a imprevisibilidade e, para fazer frente a essas exigências, na formação dos profissionais de saúde deve haver mudanças na relação ensino-aprendizado, tornando-a adequada às características deste processo ${ }^{13}$.

A educação permanente da equipe de enfermagem exige, além de programas educacionais baseados em definição de competências específicas, processos educativos críticos que visem o desenvolvimento de conhecimentos de caráter interdisciplinar, contudo, o processo encontra dificuldades em relação à iniciativa dos gestores ${ }^{14}$.

Sob tal perspectiva, tem-se a necessidade de transformações nos modelos de formação dos profissionais.

\section{A Importâneia da educação permanente para a equipe que atua nos serviẹos de emergêneia}

$\mathrm{Na}$ categoria Importância da Educação Permanente para a equipe que atua nos Serviços de Emergência aprofundou-se as situações que relatavam a importância desta estratégia para os profissionais de saúde.

No quadro 4 apresenta-se as publicações associadas a educação permanente em saúde, segundo autoria, objetivos e principais resultados da categoria Importância da Educação Permanente para a Equipe que atua nos Serviços de Emergência.

Alguns autores em estudo sobre percepção da educação permanente, continuada e em serviço 
para enfermeiros de um hospital de ensino destacam que na educação em serviço destacamse quatro áreas de atuação, sendo a primeira a orientação ou introdução ao trabalho; treinamento; atualização; e aperfeiçoamento, aprimoramento ou desenvolvimento ${ }^{15}$. Neste pensamento, afirmam que a importância da educação permanente efetiva na busca de propostas educativas que motivem ao autoconhecimento, aperfeiçoamento e atualização onde propõem o desenvolvimento de pensamento crítico ainda na graduação.

É de conhecimento que esses serviços de atendimento contam com uma equipe de profissionais de diversas áreas que devem ser habilitados pelos Núcleos de Educação em Urgências, que têm como principal objetivo promover a capacitação e educação permanente dos trabalhadores para o adequado atendimento às urgências, em todos os níveis de atenção do sistema. Assim, esse processo de ensino e aprendizagem não se faz somente pela transferência de conteúdos técnicos, normas e protocolos, mas, sobretudo, deve levar em conta as experiências vivenciadas pelos indivíduos e sua bagagem profissional e pessoal ${ }^{16}$.

Conforme se constatou em estudo ${ }^{16}$ realizado em Serviço de Atendimento Móvel de Urgência, o cenário do serviço de urgência e emergência é imperativo que os profissionais tenham formação polivalente e orientada para a visão da realidade, pois ininterruptamente se deparam com situações que exigem aptidões, além do conhecimento técnico. É necessário saber lidar com situações nas quais devem estar sempre presentes a criatividade, a qualidade de observação e a tomada de atitude. Respondendo a essa necessidade o processo ensino-aprendizagem ajustando-se à complexidade e à imprevisibilidade que são características do processo de trabalho em saúde ${ }^{16}$.

A qualificação das equipes, bem como as experiências prévias na área de urgência/emergência são fatores primordiais e essenciais que garantem o sucesso do atendimento. E para que isso ocorra, uma das propostas atuais, segundo estudo realizado com enfermeiros de atendimento pré-hospitalar móvel é a Educação Permanente, onde a capacitação do funcionário se faz no seu local de trabalho, promovendo a transformação do potencial do profissional em comportamentos objetivos, além de oferecer condições para que interprete e utilize a realidade que o cerca, pois o preparo insuficiente dos recursos humanos gera insegurança e angústia em relação ao processo de cuidar ${ }^{17}$.

Observa-se, pois, que os resultados que alimentam esta categoria caminham ao encontro dos argumentos do Ministério da Saúde ${ }^{18}$, os quais defendem que, ao se colocar em evidência a formação e o desenvolvimento para o SUS por meio da construção da educação permanente, propõe-se a agregação entre desenvolvimento individual e institucional, entre serviços e gestão setorial, permitindo a qualificação dos profissionais da área.

Dessa forma, concordamos que os profissionais que assistem no serviço de emergência devem ser preparados com alto nível de técnico - cientifico para atender aos pacientes acometidos por causas externas. Assim, a educação continuada e permanente nesse setor hospitalar possibilita maior autonomia aos profissionais da equipe de saúde, sendo fundamental inseri-la na rotina de trabalho para que se torne efetiva, ampla intimidade entre formação, gestão, atenção e participação na área especifica de saberes e de práticas ${ }^{19-20}$.

\section{Conelusão}

A análise dos estudos selecionados permitiu verificar que a Educação Permanente em Saúde no serviço de emergência é proposta como uma forma de transformação do serviço, promovendo a incorporação do aprender e ensinar ao cotidiano das práticas dos profissionais envolvidos com a saúde, proporcionando elementos para que identifiquem as necessidades de formação, transformando as práticas de educação na saúde e constituam estratégias que amenizem as necessidades dos enfermeiros deste setor. A EPS surge para aperfeiçoar a prática educacional em saúde, tendo o processo de trabalho, para o preenchimento de lacunas na formação dos profissionais e para prepará-los às especificidades que o atendimento hospitalar exige.

A realização desta pesquisa tem sua relevância pautada na carência de resultados/pesquisas 
sobre a utilização da educação permanente nos serviços de emergência e contribuições que poderá trazer para a gestão e para os profissionais de saúde deste setor, em especial a equipe de enfermagem, foco deste trabalho, na medida em que encontrando os fatores que restringem a participação dos trabalhadores nas atividades de Educação Permanente, poder-se-á buscar estratégias que motivem essa participação, promovendo uma maior adesão ao processo.

Às lacunas demonstradas e os resultados apresentados nos artigos incluídos nesta revisão integrativa, mostra ser necessário empenharmos para o desenvolvimento de práticas educativas em saúde aos profissionais do serviço de urgência e emergência, bem como o desenvolvimento de pesquisas com delineamentos que produzam evidências relativas ao tema investigado.

\section{Referêneias}

1. Montanha D, Peduzzi M. Educação permanente em enfermagem: levantamento de necessidades e resultados esperados segundo a concepção dos trabalhadores. Rev Esc Enferm USP. 2010; 44(3):597-604.

2. Destro MRP. Educação continuada: visão histórica e tentativa de contextualização. Cad Cedes Educ Continuada 1995; (36):21-7.

3. Oliveira MAN. Educação à distância como estratégia para a educação permanente em saúde: possibilidades e desafios. Rev Bras Enferm. 2007; 60(5):585-89.

4. Ministério da Saúde (BR). Secretaria de Gestão do Trabalho e da Educação na Saúde. Departamento de Gestão da Educação em Saúde. Política Nacional de Educação Permanente em Saúde. Brasília: Ministério da Saúde; 2009.

5. Ministério da Saúde (BR).Política Nacional de Atenção às Urgências. $3^{a}$ ed. Brasília: Ministério da Saúde; 2006.

6. Ministério da Saúde (BR).Portaria n. 2048/GM, de 5 de novembro de 2002. Regulamento técnico dos sistemas estaduais de urgência e emergência. $3^{\text {a }}$ ed. Brasília: Ministério da Saúde; 2006.

7. Santos NCM. Urgência e emergência para enfermagem: do atendimento pré-hospitalar (APH) à sala de emergência. São Paulo: Editora Iátria; 2008.

8. Medeiros AC, Pereira QLC, Siqueira HCH, Cecagno D, Moraes CL. Gestão participativa na educação permanente em saúde: olhar das enfermeiras. Rev Bras Enferm. 2010;63(1):38-42.

9. Gomes R, Mendonça EA, Pontes ML. As representações sociais e a experiência da doença. Cad Saúde Pública. 2002; 18(5):1207-14.
10. Zandomenighi RC, Mouro DL, Martins EAP. Ferimento por arma branca: perfil epidemiológico dos atendimentos em um pronto socorro. RevRene. 2011; 12(4):669-77.

11. Deslandes SF.Frágeis deuses: profissionais da emergência entre os danos da violência e a recriação da vida. Rio de Janeiro: Fiocruz,2002.

12. Lima SBS de,Erdmann MCPD. A enfermagem no processo de acreditação hospitalar em um serviço de urgência e emergência. Acta Paulista de Enfermagem. 2006; 19(3):27178.

13. Silva KL, Sena RR de. A educação de enfermagem: buscando a formação crítico-reflexiva e as competências profissionais. Rev Latino-am Enfermagem.2006;14(5):75561.

14. Tavares CMM. A educação permanente da equipe de enfermagem para o cuidado nos serviços de saúde mental. Texto Contexto Enferm. 2006; 15(2):287-95.

15. Paschoal AS, Mantovani MF, Meier MJ. Percepção da educação permanente, continuada e em serviço para enfermeiros de um hospital de ensino. Rev Esc Enferm USP.2007; 41(3):478-84.

16. Ciconet RM,Marques GQ,Lima MADS. Educação em serviço para profissionais de saúde do Serviço de Atendimento Móvel de Urgência (SAMU): relato da experiência de Porto Alegre-RS. Interface Comu Saúde Educ.2008; 12(26):659-66.

17. Bueno AA, Bernardes A. Percepção da equipe de enfermagem de um serviço de atendimento pré-hospitalar móvel sobre o gerenciamento de enfermagem. Texto Contexto Enferm. 2010; 19(1):45-53.

18. Ministério da Saúde (BR). Secretária de gestão do trabalho e da educação na saúde. Departamento de gestão da educação na saúde. Política de educação e desenvolvimento para o SUS: caminhos para a educação permanente em saúde: pólos da educação permanente em saúde. Brasília (DF): Ministério da Saúde; 2004.

19. Poll MA, Lunardi VL, Lunardi Filho WD. Atendimento em unidade de emergência: organização e implicações éticas. Acta Paul Enferm.2008; 21(3):509-14.

20. Ceccim RB. Educação permanente em saúde: descentralização e disseminação de capacidade pedagógica na saúde. Ciênc Saúde Coletiva.2005; 10(4):975-86. 